\title{
A Determinação da Densidade de Sólidos e Líquidos
}

\author{
Janaína César \\ Marco-Aurélio De Paoli \\ João Carlos de Andrade * \\ dandrade@iqm.unicamp.br \\ Universidade Estadual de Campinas, Instituto de Química
}

Experimento testado por Alana dos Reis Figueiredo

\section{Informações do Artigo Resumo}

Histórico do Artigo Muitos estudantes pensam que a densidade é apenas o resultado de Criado em Julho de 2004 uma operação aritmética de divisão entre a massa e o volume de uma substância, mas esse conceito é muito mais amplo e está relacionado a outros, como compressão e empacotamento. Por exemplo, quanto maior for o empacotamento dos átomos, mais densa é a substância. Da mesma forma, quanto maior for a compressão sobre um objeto, maior será a sua densidade. Nesse trabalho serão abordados apenas os aspectos mais diretos

Palavras-Chaves

Densidade

Densidade Absoluta

Densidade Relativa

Propriedades químicas

Propriedades físicas e as técnicas de laboratório mais comuns envolvidas na determinação da densidade de sólidos e líquidos, mas vale a pena buscar um detalhamento mais profundo sobre o conceito de densidade. O experimento proposto, de caráter conceitual e metodológico, tem uma duração prevista de duas horas de atividades em laboratório, com baixo grau de risco.

Chemkeys. Licenciado sob Creative Commons (BY-NC-SA)

\section{Introdução}

As propriedades dos materiais são agrupadas em químicas e físicas. As propriedades químicas descrevem uma transformação química, tal como a interação de uma substância com outra, ou a transformação de uma substância em outra. As propriedades físicas não envolvem qualquer mudança na composição ou identidade da substância, isto é, são propriedades que podem ser observadas e medidas sem modificação de sua composição. As propriedades físicas podem ser classificadas como extensivas ou intensivas.

As propriedades extensivas são diretamente proporcionais à quantidade de matéria da substância presente da amostra, enquanto que as intensivas independem da quantidade de matéria. Temperatura $(\mathrm{T})$, pressão $(\mathrm{p})$, cor e densidade $(\mathrm{d})$ são propriedades intensivas, enquanto que massa (m) e volume $(V)$ são propriedades extensivas.

É importante ressaltar que uma propriedade extensiva pode ser convertida em uma propriedade intensiva de duas maneiras: 1) dividindo-se a propriedade extensiva pela quantidade de matéria ou 2) dividindo-se por outra propriedade extensiva - usualmente massa ou volume. Por exemplo, a densidade, que é uma propriedade intensiva, é dada pela razão massa/volume. 


\section{Definições e conceitos [2]}

A densidade absoluta ( $\rho$ ) de uma substância é definida [2] como a relação entre a sua massa e o seu volume:

$$
\rho=m / v
$$

Adensidadeabsolutaétambémuma propriedade específica, isto é, cada substância pura tem uma densidade própria, que a identifica e a diferencia das outras substâncias.

A densidade relativa

$$
d=\rho / \rho^{0}
$$

de um material é a relação entre a sua densidade absoluta e a densidade absoluta de uma substância estabelecida como padrão. No cálculo da densidade relativa de sólidos e líquidos, o padrão usualmente escolhido é a densidade absoluta da água, que é igual a $1,000 \mathrm{~kg} \mathrm{dm}^{-3}$ (equivalente a $1,000 \mathrm{~g} \mathrm{~cm}^{-3}$ ) a $4^{\circ} \mathrm{C}$, dado por

$$
\rho^{0}=\rho\left(\mathrm{H}_{2} \mathrm{O}, 4^{\circ} \mathrm{C}\right)
$$

No caso de gases, a densidade relativa é tomada em relação ao ar ou ao hidrogênio.

Tabela 1 - Grandezas, símbolos e unidades.

\begin{tabular}{|l|l|l|l|}
\hline $\begin{array}{l}\text { Nome da } \\
\text { Grandeza }\end{array}$ & Símbolo & $\begin{array}{l}\text { Nome da } \\
\text { Unidade }\end{array}$ & Símbolo \\
\hline Densidade & $\rho$ & $\begin{array}{l}\text { quilograma por } \\
\text { metro cúbico }\end{array}$ & $\mathrm{kg} \mathrm{\textrm {m } ^ { - 3 }}$ \\
\hline Densidade relativa & $\mathrm{d}$ & adimensional & ----- \\
\hline Massa & $\mathrm{m}$ & quilograma & $\mathrm{kg}$ \\
\hline Volume & $\mathrm{V}$ & metro cúbico & $\mathrm{m}^{3}$ \\
\hline Temperatura & $\mathrm{T}$ & kelvin & $\mathrm{K}$ \\
\hline Pressão & $\mathrm{p}$ & pascal & $\mathrm{Pa}$ \\
\hline
\end{tabular}

A densidade é uma propriedade física importante e pode ser utilizada para distinguir um material puro de um impuro (ou de ligas desse metal), pois a densidade dos materiais que não são puros (misturas) é uma função da sua composição. Ela também pode ser utilizada na identificação e no controle de qualidade de um determinado produto industrial, bem como ser relacionada com a concentração de soluções.

A densidade de um sólido pode ser determinada pesando- $0^{1}$ cuidadosamente e em seguida determinando seu volume. Se o sólido apresentar uma forma irregular (o que torna impossível medir suas dimensões), o volume poderá ser determinado utilizando um método de deslocamento [3]. Basicamente, determina-se a massa de uma amostra do

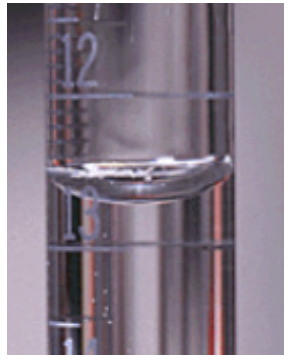

Figura 1: Representação da posição do menisco.

sólido e então transfere-se quantitativamente essa massa para um instrumento volumétrico graduado apropriado (ex: proveta ou bureta), parcialmente cheio com água (ou em algum líquido no qual o sólido não flutue). $\mathrm{O}$ sólido deslocará um volume de líquido igual ao seu volume. Assim, ao anotar a posição do menisco ${ }^{2}$ (Figura 1) [4] antes e depois da adição do sólido, o volume poderá ser deduzido [5].

A densidade dos líquidos pode ser determinada analogamente à densidade dos sólidos, medindo-se a sua massa e determinando-se o seu volume. Entretanto, no caso dos líquidos, uma alteração relativamente pequena na temperatura pode afetar consideravelmente o valor da densidade, enquanto que a alteração de pressão tem que ser relativamente alta para que o valor da densidade seja afetado [6].

A densidade apresenta variações periódicas com o número atômico, mas essas variações não são regulares, já que a relação entre as propriedades físicas e a configuração eletrônica não é direta [7]. Pense nisso! (Descreva em seu relatório, de uma forma breve, que conclusões podem ser retiradas desta afirmação).

\footnotetext{
${ }^{1}$ A pesagem é um procedimento necessário em quase todas as análises, seja para a medida do tamanho da amostra, seja no preparo de soluçõespadrão, dentre outros. Em um trabalho de rotina, as massas pesadas podem variar de vários gramas a alguns miligramas, ou menos. O conhecimento dos procedimentos de pesagem são detalhes importantes a serem considerados. Quando a quantidade de substância a ser pesada não requer precisão, pode-se empregar uma balança com duas ou três casas decimais, equivalentes a precisões entre $\pm 1 \mathrm{mg}$ e $\pm 10 \mathrm{mg}$. Se forem necessárias pesagens mais precisas, deve-se empregar balanças analíticas, com um precisão de pelo menos $\pm 0,1 \mathrm{mg}$ (quatro casas decimais).

2 A leitura correta do menisco deve ser feita na perpendicular, para evitar os erros de paralaxe. O ponto máximo ou mínimo da curvatura do menisco é que deve ser usado como referência para a leitura da magnitude do volume que está sendo medido. Por que o menisco é curvo? A resposta termodinâmica para essa pergunta é discutida na referência [4].
} 


\section{Reagentes e Materiais}

Os reagentes e materiais (Figura 2) necessários para esse experimento são:

- Balança analítica ${ }^{3}$ (Figura 3)

- Uma proveta de $10,0 \mathrm{~mL}$

- Um picnômetro ${ }^{4}$ (Figura 4) de $25,0 \mathrm{~mL}$

- Um béquer de $50,0 \mathrm{~mL}$ e dois béqueres de $250,0 \mathrm{~mL}$

- Uma Pisseta

- Água destilada

- Bico de Bunsen

- Tripé

- Tela de amianto

- Caixa de fósforos (ou similar)

- Pregos (de ferro ou de aço), aparas de alumínio e fios de cobre. O tamanho das amostras devem apresentar dimensões compatíveis com as dimensões das vidrarias utilizadas (proveta e picnômetro).

- Leite (O ideal seria que metade dos alunos determinassem a densidade de uma amostra de leite integral e a outra metade de leite desnatado)

- Álcool comercial

- Termômetro

- Tiras de papel higiênico

- Pinça

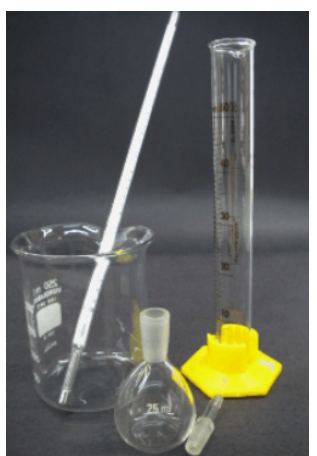

(a)

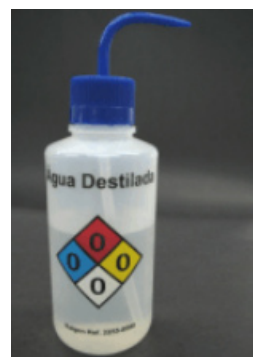

(b)
Figura 2: Materiais necessários para o experimento. (a) vidrarias; (b) pisseta de $250 \mathrm{~mL}$.

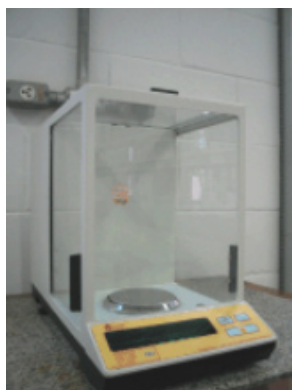

Figura 3: BalançaAnalítica.

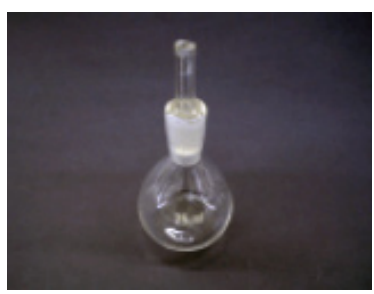

Figura 4: Picnômetro
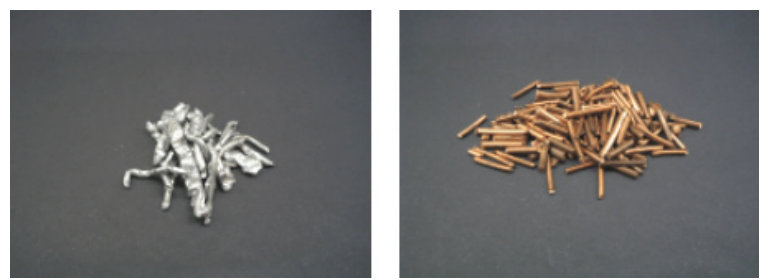

Figura 5: A paras de alumínio (esquerda) e fios de cobre (direita).

\section{Procedimento Experimental}

Medidas da densidade de sólidos

Neste experimento você trabalhará com diferentes metais os quais apresentarão diferentes formas. O objetivo é que você determine a densidade de cada amostra (utilizando proveta e picnômetro) e que posteriormente se faça uma comparação entre os resultados obtidos e uma tabela de densidades conhecidas [6]. Pense nisso! (Descreva em seu relatório outros métodos para se determinar a densidade de sólidos)

\footnotetext{
${ }^{3}$ A balança analítica é um dos instrumentos de medida mais usados no laboratório e dela dependem basicamente todos os resultados analíticos. As balanças analíticas modernas, que podem cobrir faixas de precisão de leitura da ordem de $0,1 \mu \mathrm{g}$ a $0,1 \mathrm{mg}$, já estão bastante aperfeiçoadas a ponto de dispensarem o uso de salas especiais para a pesagem. Mesmo assim, o simples emprego de circuitos eletrônicos não elimina as interações do sistema com o ambiente. Destes, os efeitos físicos são os mais importantes, pois não podem ser suprimidos.

${ }^{4}$ É principalmente utilizado para determinar a densidade de amostras líquidas, mas eventualmente pode ser usado em amostras sólidas. São feitos de vidro resistente, com baixo coeficiente de expansão térmica. Existem vários modelos diferentes, porém o mais comum é o mostrado na figura ao lado. É apresentado geralmente em volumes de $25,0 \mathrm{~mL}$ ou $50,0 \mathrm{~mL}$ e tem precisão até a quarta casa decimal.
} 
a) Utilizando a proveta

- Pese aproximadamente 5,000g de pregos(s) e anote sua massa. Com o auxílio de uma pisseta, coloque água destilada na proveta até aproximadamente a metade de sua capacidade total. Ajuste o menisco e anote o volume.

- Introduza o(s) prego(s) na proveta (sugestão: incline a proveta num ângulo de aproximadamente $30^{\circ}$ ao introduzir a amostra, para evitar o impacto entre a amostra e o fundo da proveta e para impedir que parte da água destilada espirre para fora)

- Anote o novo volume. (sugestão: anote o novo volume após bater levemente na lateral da proveta algumas vezes para eliminar bolhas de ar que eventualmente tenham ficado retidas na superfície da amostra).

- Meça a diferença entre o volume inicial e o volume final, esta medida fornecerá o volume da amostra.

- Com os resultados obtidos acima, calcule a densidade da amostra.

- Compare a densidade calculada para o prego com a Tabela 2.

- Repita a operação para as demais amostras (aparas de alumínio e fios de cobre), anotando os valores encontrados para cada uma delas na Tabela 5.

Tabela 2 - Densidades aproximadas de algumas substâncias [8]

\begin{tabular}{|l|l|l|l|}
\hline Substância & $\begin{array}{l}\text { Densidade } \\
\left(\mathbf{g ~ c m}^{-3}\right)\end{array}$ & Substância & $\begin{array}{l}\text { Densidade } \\
\left(\mathbf{g ~ c m}^{-3}\right)\end{array}$ \\
\hline Álcool & 0,79 & Níquel & 8,9 \\
\hline Alumínio & 2,7 & Platina & 21,4 \\
\hline Latão & 8,4 & Porcelana & 2,4 \\
\hline Cobre & 8,9 & Prata & 10,5 \\
\hline Vidro & 2,6 & Aço inoxidável & 7,9 \\
\hline Ouro & 19,3 & Água & 1,0 \\
\hline Ferro & 7,9 & Estanho & 7,26 \\
\hline Mercúrio & 13,6 & & \\
\hline
\end{tabular}

\section{b) Utilizando o picnômetro}

O picnômetro deve ser previamente calibrado, conforme as instruções abaixo:

- Em um béquer de 250,0mL limpo, coloque aproximadamente $150,0 \mathrm{~mL}$ de água destilada. Aguarde algum tempo (até atingir o equilíbrio térmico à temperatura ambiente) e, com o auxílio de um termômetro de mercúrio, meça a temperatura da água.

- Pese cuidadosamente o picnômetro vazio e seco. Anote sua massa. Utilize um pedaço de papel para carregar o picnômetro.

- Complete o picnômetro com água destilada do béquer. Tampe o picnômetro de maneira que o excesso de água escorra pelo capilar. Verifique se bolhas de ar não ficaram aprisionadas no interior do picnômetro. Se isso ocorreu, remova-as e preencha-o novamente. Coloque o picnômetro preenchido dentro do béquer contendo o restante da água destilada, evitando que o nível de água do béquer atinja a tampa do picnômetro. Aguarde 15 minutos para que se atinja o equilíbrio térmico. Verifique novamente e anote a temperatura da água no béquer. Através da Tabela 3, determine a densidade da água nessa temperatura. Interpolar para frações de grau Celsius, se necessário.

- Com um pano ou papel poroso, enxugue o líquido presente na parte externa do picnômetro.

- Pese o picnômetro com água. Anote a massa. Utilize um pedaço de papel para carregar o picnômetro.

- Repita a pesagem mais duas vezes retirando o picnômetro da balança a cada pesagem. Atenção! Procure realizar esta operação o mais delicada e rapidamente possível, para não sujar ou engordurar as paredes externas do picnômetro e para evitar que o líquido mude de temperatura com relação à ambiente.

- A diferença entre essa massa e a massa do picnômetro vazio permitirá determinar a massa de água contida no picnômetro.

- Complete a Tabela 6 com os dados obtidos e determine a capacidade do picnômetro.

Tabela 3 - Densidade absoluta da água [8]

\begin{tabular}{|l|l|l|l|}
\hline $\mathbf{T}\left({ }^{\circ} \mathbf{C}\right)$ & $\mathbf{d} /\left(\mathbf{g ~ c m}^{-3}\right)$ & $\mathbf{T}\left({ }^{\circ} \mathbf{C}\right)$ & $\mathbf{d} /\left(\mathbf{g ~ c m}^{-3}\right)$ \\
\hline 10 & 0,999700 & 20 & 0,998203 \\
\hline 11 & 0,999605 & 21 & 0,997992 \\
\hline 12 & 0,999498 & 22 & 0,997770 \\
\hline 13 & 0,999377 & 23 & 0,997538 \\
\hline 14 & 0,999244 & 24 & 0,997296 \\
\hline 15 & 0,999099 & 25 & 0,997044 \\
\hline 16 & 0,998943 & 26 & 0,996783 \\
\hline 17 & 0,998774 & 27 & 0,996512 \\
\hline 18 & 0,998595 & 28 & 0,996232 \\
\hline 19 & 0,998405 & 29 & 0,995944 \\
\hline
\end{tabular}

Atenção: Utiliza-se geralmente água para a calibração dos instrumentos utilizados em densimetria, porém as medida de densidade são afetadas pela variação da temperatura. Para a água à temperatura ambiente, a densidade decresce cerca de $0,03 \%$ por ${ }^{\circ} \mathrm{C}$ de aumento de temperatura [9].

Para a determinação da densidade das amostras sólidas: 
- Lave o picnômetro com álcool.

- Determine a massa do picnômetro vazio, após secálo. Utililize um pedaço de papel para carregar o picnômetro.

- Adicione o(s) prego(s). Coloque água destilada até aproximadamente metade do volume do picnômetro e mergulhe-o em um béquer contendo água destilada em ebulição para remover as bolhas de ar que ficaram aderidas na superfície do sólido.

- Mergulhe o picnômetro em um béquer com água à temperatura ambiente durante 10 minutos. Troque a água do béquer algumas vezes durante este período.

- Retire o picnômetro do béquer, preencha-o com água destilada. É importante tomar cuidado ao encher o frasco com a água, para não ocorrer formação de bolhas. Isso acarretaria erros nos resultados.

- Coloque a tampa de maneira que o excesso de água escorra pelo capilar. Com um pano ou papel poroso, enxugue o líquido presente na parte de fora do picnômetro.

- Pese novamente o picnômetro contendo (amostra + água destilada) e anote sua massa. Pese mais duas vezes retirando o picnômetro da balança a cada pesagem. Utililize um pedaço de papel para carregar o picnômetro.

- Repita a operação para as demais amostras (aparas de alumínio e fios de cobre).

- Construa uma tabela semelhante à Tabela 7 para cada uma das amostras (prego, $\mathrm{Al} \mathrm{e} \mathrm{Cu}$ ) e calcule os valores de suas densidades.

- Complete a Tabela 8 com os dados obtidos na Tabela 7.

\section{Medidas da densidade de líquidos}

a) A determinação da densidade do álcool comercial

Além de ser amplamente utilizado como combustível, o álcool também está presente na indústria farmacêutica, de cosméticos, de higiene e limpeza e como solvente na indústria de tintas e vernizes.

O poder bactericida desse composto, associado ao seu poder solubilizante, à sua alta taxa de evaporação e ao seu baixo custo, fazem do álcool etílico um dos produtos de higiene e limpeza mais procurados pelo mercado consumidor final. Além disso, o álcool etílico é encontrado na composição de bebidas alcoólicas, obtidas pela fermentação de açúcares.

b) Procedimento
- Determine a massa do picnômetro vazio e calibre-o (veja o item discutido acima).

- Lave três vezes o picnômetro com um pequeno volume do líquido cuja densidade será determinada (álcool comercial) para remover os resíduos de água do seu interior. Descarte estas alíquotas num local apropriado.

- Adicione o álcool (sugestão: ao encher o frasco com álcool, tome cuidado para não haver a formação de bolhas, pois isto acarretaria erros nos resultados) e coloque a tampa de maneira que o excesso de líquido escorra pelo capilar. Com um pano ou papel poroso, enxugue o líquido presente na parte externa do picnômetro.

- Pese o picnômetro (contendo o líquido) e anote sua massa. Repita a pesagem mais duas vezes retirando o picnômetro da balança a cada pesagem. Utilize um pedaço de papel para carregar o picnômetro.

- Meça a temperatura do líquido.

- Complete a Tabela 9. A diferença entre essa massa e a massa do picnômetro vazio permitirá determinar a massa do álcool. Como o volume do álcool corresponde ao volume do picnômetro determinado durante a calibração, a densidade do álcool poderá ser facilmente determinada.

\section{c) A determinação da densidade do leite}

Por quê o leite ? Desde o nascimento do ser humano, o leite apresenta-se quase indissociável de sua alimentação. A melhoria na qualidade de vida do ser humano é ressaltada pela vital necessidade de se ter alimentos saudáveis. O leite é constituído principalmente por água, gordura, vitaminas, proteínas, enzimas, lactose e substâncias minerais. A Tabela 4 apresenta a composição média do leite de vaca. A densidade do leite varia entre $1,023 \mathrm{~g} \mathrm{~mL}$ ${ }^{1} \mathrm{e} 1,040 \mathrm{~g} \mathrm{~mL}^{-1}$, a $15^{\circ} \mathrm{C}$. O valor médio é $1,032 \mathrm{~g} \mathrm{~mL}^{-1}$. O leite com alto teor de gordura apresenta maior densidade em relação ao leite com baixo teor de gordura [10].

Tabela 4 - Composição média do leite de vaca [10]

\begin{tabular}{|l|l|l|}
\hline Constituinte & Teor $\left(\mathbf{g ~ k g}^{-1}\right)$ & Variação $\left(\mathbf{g ~ k g}^{-1}\right)$ \\
\hline Água & 873 & $855-887$ \\
\hline Lactose & 46 & $38-53$ \\
\hline Gordura & 39 & $24-55$ \\
\hline Proteínas & 32,5 & $23-44$ \\
\hline Substâncias minerais & 6,5 & $5,3-8,0$ \\
\hline Ácidos orgânicos & 1,8 & $1,3-2,2$ \\
\hline Outros & 1,4 & \\
\hline
\end{tabular}


d) Procedimento

- Lave o picnômetro com álcool.

- Determine a massa do picnômetro vazio, após secálo.

- Lave três vezes o picnômetro com um pequeno volume do líquido cuja densidade será determinada (leite) para remover os resíduos do seu interior. Descarte estas alíquotas num local apropriado.

- Adicione o leite (atenção: É importante tomar cuidado ao encher o frasco com o leite para não haver formação de bolhas, pois isto acarretaria erros nos resultados) e coloque a tampa de maneira que o excesso de líquido escorra pelo capilar. Com um pano ou papel poroso, enxugue o líquido presente na parte externa do picnômetro.

- Pese o picnômetro (contendo o líquido) e anote sua massa. Repita a pesagem mais duas vezes retirando o picnômetro da balança a cada pesagem. Utililize um pedaço de papel para carregar o picnômetro.

- Meça a temperatura do líquido.

- Complete a Tabela 10. A diferença entre essa massa e a massa do picnômetro vazio permitirá determinar a massa do leite. E, como o volume do leite corresponde ao volume do picnômetro determinado durante a calibração, a densidade do leite poderá ser facilmente determinada.

Pense nisso! (Descreva em seu relatório outros métodos que poderiam ser utilizados para se determinar a densidade de líquidos).

As possíveis fontes de erros do método [9] são:

- Evaporação do líquido durante a pesagem. Líquidos voláteis precisam de picnômetros com tampa no braço lateral.

- Absorção de umidade ambiente na superfície do frasco durante a pesagem.

- Flutuações de temperatura.

- Presença de bolhas de ar.
Tabela 5 - Resultados referentes à determinação da densidade de sólidos

\begin{tabular}{|l|l|l|l|}
\hline Amostra & Prego & Alumínio & Cobre \\
\hline Massa (g) & & & \\
\hline $\begin{array}{l}\text { Volume Inicial } \\
(\mathrm{mL})\end{array}$ & & & \\
\hline $\begin{array}{l}\text { Volume final } \\
(\mathrm{mL})\end{array}$ & & & \\
\hline $\begin{array}{l}\text { Volume Deslocado } \\
(\mathrm{mL})\end{array}$ & & & \\
\hline $\begin{array}{l}\text { Densidade } \\
(\mathrm{g} \mathrm{mL}-1)\end{array}$ & & & \\
\hline
\end{tabular}

b) Medidas da densidade de sólidos utilizando o picnômetro

Tabela 6 - Resultados referentes à calibração do picnômetro.

\begin{tabular}{|l|l|l|}
\hline Grandeza & Representação & Resultado \\
\hline Massa do picnômetro vazio & $\mathrm{m}_{\mathrm{PV}}$ & \\
\hline $\begin{array}{l}\text { Massa do picnômetro com } \\
\text { água }\end{array}$ & $\mathrm{m}_{\mathrm{PA}}$ & \\
\hline Massa da água & $\mathrm{m}_{\mathrm{H} 2 \mathrm{O}}=\left(\mathrm{m}_{\mathrm{PA}}\right)-\left(\mathrm{m}_{\mathrm{PV}}\right)$ & \\
\hline Temperatura da água & $\mathrm{T}$ & \\
\hline Densidade da água & $\mathrm{d}_{\mathrm{H} 2 \mathrm{O}}$ & \\
\hline
\end{tabular}

Tabela 7 - Resultados referentes a determinação da densidade de sólidos

\begin{tabular}{|l|l|l|}
\hline Grandeza & Representação & Resultado \\
\hline $\begin{array}{l}\text { Massa do picnômetro } \\
\text { vazio }\end{array}$ & $\mathrm{m}_{\mathrm{PV}}$ & \\
\hline $\begin{array}{l}\text { Massa (picnômetro + } \\
\text { amostra) }\end{array}$ & $\mathrm{m}_{\mathrm{PA}}$ & \\
\hline Massa da amostra & $\mathrm{m}_{\mathrm{A}}=\left(\mathrm{m}_{\mathrm{PA}}\right)-\left(\mathrm{m}_{\mathrm{PV}}\right)$ & \\
\hline $\begin{array}{l}\text { Massa (picnômetro + } \\
\text { amostra + água) }\end{array}$ & $\mathrm{m}_{\text {total }}$ & \\
\hline Massa da água & $\mathrm{m}_{\mathrm{H} 2 \mathrm{O}}(\mathrm{ad})=\left(\mathrm{m}_{\mathrm{total}}\right)-\left(\mathrm{m}_{\mathrm{PA}}\right)$ & \\
\hline Volume da água & $\mathrm{V}_{\mathrm{H} 2 \mathrm{O}}=\mathrm{m}_{\mathrm{H} 2 \mathrm{O}}(\mathrm{ad}) / \mathrm{d}_{\mathrm{H} 2 \mathrm{O}}$ & \\
\hline Volume da amostra & $\mathrm{V}_{\mathrm{A}}=\left(\mathrm{V}_{\mathrm{P}}\right)-\left(\mathrm{V}_{\mathrm{H} 2 \mathrm{O}}\right)$ & \\
\hline
\end{tabular}

Tabela 8 - Densidade dos sólidos utilizando picnômetro

\begin{tabular}{|l|l|l|l|}
\hline Amostra & Prego & Alumínio & Cobre \\
\hline $\begin{array}{l}\text { Densidade Absoluta } \\
\left(\mathrm{g} \mathrm{mL} \mathrm{m}^{-1}\right)\end{array}$ & & & \\
\hline
\end{tabular}

\section{Resultados}

\section{Densidade de sólidos}

a) Medidas da densidade de sólidos utilizando a proveta
Densidade de líquidos

Tabela 9 - Resultados referentes ao álcool comercial

\begin{tabular}{|l|l|l|}
\hline Grandeza & Representação & Resultado \\
\hline Massa do picnômetro vazio & $\mathrm{m}_{\mathrm{PV}}$ & \\
\hline
\end{tabular}




\begin{tabular}{|l|l|l|}
\hline $\begin{array}{l}\text { Massa (picnômetro + } \\
\text { ácool) }\end{array}$ & $\mathrm{m}_{\mathrm{PA}}$ & \\
\hline Massa do álcool & $\mathrm{m}_{\text {álcool }}=\left(\mathrm{m}_{\mathrm{PA}}\right)-\left(\mathrm{m}_{\mathrm{PV}}\right)$ & \\
\hline Volume do álcool & $\mathrm{V}_{\text {álcool }}$ & \\
\hline Densidade do álcool & $\mathrm{d}_{\text {álcool }}$ & \\
\hline
\end{tabular}

Tabela 10 - Resultados referentes ao leite

\begin{tabular}{|l|l|l|}
\hline Grandeza & Representação & Resultado \\
\hline $\begin{array}{l}\text { Massa do picnômetro } \\
\text { vazio }\end{array}$ & $\mathrm{m}_{\mathrm{PV}}$ & \\
\hline Massa (picnômetro + leite) & $\mathrm{m}_{\mathrm{PL}}$ & \\
\hline Massa de leite & $\mathrm{m}_{\text {leite }}=\left(\mathrm{m}_{\mathrm{PL}}\right)-\left(\mathrm{m}_{\mathrm{PV}}\right)$ & \\
\hline Volume de leite & $\mathrm{V}_{\text {leite }}$ & \\
\hline Densidade do leite & $\mathrm{d}_{\text {leite }}$ & \\
\hline
\end{tabular}

Segurança

\section{Precauções}

- Leia todas as instruções relacionadas à experiência que irá realizar.

- Verifique os "Material Safety Data Sheet"-MSDS-das substâncias envolvidas no trabalho de laboratório.

- Trabalhe cuidadosamente com as vidrarias.

- Conserve limpa sua bancada. Evite derramar líquidos, mas, se o fizer, lave imediatamente o local.

- Equipamentos de Proteção Individual (EPI) necessários: óculos e avental.

- Ao término do período de laboratório, lave todas as vidrarias utilizadas e deixe-as da mesma forma em que se encontrou no início da aula.

\section{Descarte de resíduos}

- Descarte a água destilada na pia do laboratório.

- O leite, como já foi manipulado, não poderá mais ser consumido. Portanto, deverá ser descartado conforme orientação do professor responsável.

- O álcool comercial poderá ser descartado num recipiente apropriado para: a) posteriormente ser utilizado como produto de limpeza ou, b) passar por um processo de destilação e ser reutilizado em outros experimentos.

Tópicos para discussão no relatório

- Em todas as determinações calcule as médias e os erros médios relativos.
- Compare os valores calculados da densidade com os valores teóricos na tabela periódica. Em cada caso, calcule o erro porcentual em relação ao valor teórico previsto e complete a Tabela 11. Explique o por quê desta diferença nos valores da densidade.

- Descreva, com suas palavras, como se utiliza um picnômetro.

- Quais os erros mais comuns que podem ser cometidos no uso do picnômetro? Você acha viável determinar a densidade de sólidos utilizando esta vidraria?

- Por quê um prego afunda na água e um navio flutua?

- Certo líquido insolúvel na água tem densidade igual a 1,200 g mL-1. Esse líquido deve flutuar ou afundar na água? Por quê?

Tabela 11 - Valores de densidade com seus respectivos erros relativos

\begin{tabular}{|c|c|c|c|c|}
\hline & Metal & Ferro & Alumínio & Cobre \\
\hline & $\begin{array}{l}\text { Densidade Tabelada } \\
\left(\mathrm{g} \mathrm{mL}^{-1}\right)\end{array}$ & & & \\
\hline \multirow{2}{*}{ 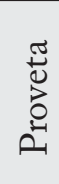 } & \begin{tabular}{|l|}
$\begin{array}{l}\text { Densidade Medida } \\
\left(\mathrm{g} \mathrm{mL}^{-1}\right)\end{array}$ \\
\end{tabular} & & & \\
\hline & \begin{tabular}{|l} 
Erro Relativo \\
$(\%)$
\end{tabular} & & & \\
\hline \multirow{2}{*}{ 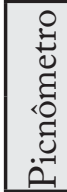 } & $\begin{array}{l}\text { Densidade Medida } \\
\left(\mathrm{g} \mathrm{mL}^{-1}\right)\end{array}$ & & & \\
\hline & $\begin{array}{l}\text { Erro Relativo } \\
(\%)\end{array}$ & & & \\
\hline
\end{tabular}

Referências Bibliográficas

1. Hawkes, S. J., "The Concept of Density", J. Chem. Educ., 2004, 81: 14-15.

2. Inczéd, J.; Lengyel. T.; Ure, A.M. (eds.), "IUPAC - Compendium of Analytical Nomenclature: Definitive Rules”, 3a. edição, Blackwell Science Ltd., Oxford, 1997, Cap. 1, pp.1-5.

3. Sterrett, F.S.K.; Kennedy, S.E.; Sparberg, E.B., "A Laboratory Investigation of Concepts in Chemistry", Harper \& Row Publishers, New York, 1968, pp.3032.

4. Henriksson, U.; Eriksson, J.C., "Thermodynamics of capillary rise: Why is the meniscus curved?", J. Chem. Educ., 2004, 81: 150-154.

5. Dickson, T.R.; Healey, J.T., "Laboratory 
Experiments for an Introduction to Chemistry"; John Wiley \& Sons, Inc.; New York, 1971, pp.13-14.

6. Sienko, M.J.; Plane, R.A., "Experimental Chemistry", 4th. edition, McGraw-Hill, New York, 1972, pp.31-35.

7. Russel, J. B., "Química Geral", Editora McGrawHill, São Paulo, 1981, pp.193-194.

8. Baccan, N.; de Andrade, J.C.; Godinho, O.E.S.; Barone, J.S., "Química Analítica Quantitativa Elementar", 3aed., 3a reimpressão, Editora Edgard Blücher Ltda, São Paulo, 2003, p.292.

9. Cecchi, H. M., "Fundamentos teóricos e práticos em análise de alimentos", 2a ed. Revisada, Editora Unicamp, Campinas, 2003, pp. 98-100.

10. Silva, P. H. F., "Leite: aspectos de composição e propriedades”, Química Nova na Escola, 1997, 6: 35. 